\title{
Utilização de adsorvente em rações contendo aflatoxina para alevinos de jundiá
}

\section{Paulo Rodinei Soares Lopes ${ }^{1}$, Juvêncio Luis Osório Fernandes Pouey ${ }^{2}$, Dariane Beatriz Schoffen Enke ${ }^{3}$, Carlos Augusto Mallmann ${ }^{4}$, Henrique Augusto $\mathrm{Kich}^{5}$, Marcela Bromberger Soquetta ${ }^{6}$}

\footnotetext{
1 Universidade Federal do Pampa.

2 Universidade Federal de Pelotas.

3 Doutora em Zootecnia - FAEM-UFPel.

${ }^{4}$ Universidade Federal de Santa Maria.

5 Curso de graduação em Agronomia - FAEM-UFPel.

${ }^{6}$ Curso de graduação em Engenharia Química.
}

RESUMO - Neste trabalho foi avaliado o efeito de um adsorvente (aluminossilicato de cálcio e sódio) no desempenho de alevinos de jundiá (Rhamdia quelen) alimentados com rações contendo níveis crescentes de aflatoxina. Foram utilizados 360 peixes com peso inicial de 4,2 $\pm 0,6 \mathrm{~g}$, criados em sistema de recirculação da água termorregulada, durante 90 dias, e alimentados com rações contendo um dos quatro níveis de aflatoxinas $(0,150,250$ e $350 \mu \mathrm{g} / \mathrm{kg})$, com e sem inclusão de adsorvente $(0,0,3$ e $0,6 \%)$, com três repetições. O uso de aflatoxina teve efeito negativo sobre o crescimento e o ganho de peso dos alevinos, que reduziram proporcionalmente aos níveis de aflatoxina, mas não ocasionou mortalidade. Os níveis de adsorvente na dieta não diminuíram os efeitos das aflatoxinas no desempenho dos peixes, mas diminuíram a aceitação da ração, em virtude da palatabilidade do produto. Não é recomendável a utilização de aluminossilicato de cálcio e sódio como adsorvente de aflatoxinas em rações para alevinos de jundiá.

Palavra-chave: aluminossilicato, micotoxina, nutrição, toxina

\section{Use of adsorbent in diets containing aflatoxin for silver catfish fingerlings}

\begin{abstract}
The effects of aflatoxins and one adsorbent (Sodium and calcium aluminum silicate) on silver catfish (Rhamdia quelen) fingerlings were evaluated in this study. Three hundred and sixty fish, with initial weight of $4 \mathrm{~g}$, were raised in a thermo-regulated recirculation water system, during 90 days. Twelve treatments with four aflatoxin levels in diet $(0,150,250$ and $350 \mu \mathrm{g} / \mathrm{kg})$, with and without adsorbents $(0,0.3$ and $0.6 \%)$ were tested in three replications. The results showed that the negative effect of aflatoxins significantly reduced the growth and weight gain of fingerlings, proportionately to the increasing levels of aflatoxin in diet, with mortality occurrence. The adsorbent levels in diet did not diminish the effects of aflatoxin action on fish performance due to the low inclusion and also little acceptance of ration in relation to the product palatability. It is concluded that silver catfish fingerlings fed diets containing aflatoxin are susceptible to negative effects, with high losses in growth and weight gain.
\end{abstract}

Key Words: aluminum silicate, micotoxin, nutrition, toxin

\section{Introdução}

Os custos com alimentação na aqüicultura determinam grande parte dos custos totais de produção nas criações semi-intensivas (Meer et al., 1995), uma vez que as dietas para peixes possuem elevado teor de proteína em comparação às dietas para outros animais cultivados (Furuya et al., 1997). Assim, na aquisição de ingredientes com alto padrão de qualidade nutricional para elaboração de dietas para os peixes, devem ser considerados principalmente os níveis de micotoxinas.

As micotoxinas são metabólitos tóxicos secundários, produzidos por fungos do gênero Aspergillus, espécies A. flavus e A. parasiticus (Yu et al., 2005), que contaminam alguns ingredientes utilizados em rações desde a cultura no campo até o armazenamento nos silos. As micotoxinas apresentam, de modo geral, grande estabilidade química, o que permite sua persistência no alimento mesmo após a 
remoção dos fungos pelos processos normais de industrialização e embalagem, ou seja, mesmo que o alimento sofra o processamento, a micotoxina ainda estará presente (Tristan, 2002). Os sinais da intoxicação por aflatoxinas dependem principalmente de sua concentração no alimento, do tipo de aflatoxina e do tempo de ingestão (Ogido et al., 2004). A intoxicação é caracterizada pela imunodepressão e por anomalias ósseas, hemorragias, despigmentação e alterações na função hepática (Miazzo et al., 2005).

Atualmente, a aflatoxina B1 é das mais eficazes substâncias carcinogênicas, mutagênicas e teratogênicas e tem sido identificada como fator associado ao câncer hepático, após a ingestão de alimentos contaminados, tanto em animais como no homem (Ferreira et al., 2006). Uma forma de controle da ação das micotoxinas é o uso de adsorvente na ração animal. O método ideal para detoxificação é aquele que, além de reduzir as concentrações da toxina em níveis seguros, não gere produtos de degradação tóxicos aos animais nem reduza o valor nutritivo dos alimentos tratados. Assim, poderiam ser usados adsorventes inertes na dieta com o objetivo de reduzir a absorção de aflatoxinas pelo trato intestinal dos animais.

Desde o início dos anos 90, estudos têm sido dirigidos para o uso de adsorventes, naturais ou sintéticos para reduzir os efeitos da ingestão de alimento contaminado e da toxidade da aflatoxina. Segundo Olver (1997), os adsorventes aderem à aflatoxina e impedem sua absorção pelo trato gastrintestinal, tornando-a inerte e não tóxica para os animais. Entre os adsorventes que são utilizados comercialmente, destacam-se os alumino silicatos de $\mathrm{Ca}^{++}$ e $\mathrm{Na}^{+}$, as bentonitas, os componentes da zeolitica, para o controle da aflatoxicose.

A montmorilonita sódica pertence ao grupo das argilas, classificadas como esmectitas, do grupo dos aluminosilicatos, é considerada promissora na absorção das aflatoxinas por reduzir os danos metabólicos (Tristan, 2002).

Os compostos de aluminosilicato de sódio e cálcio (ASSCA) na concentração de $0,5 \%$ na ração têm apresentado resultado significativo na diminuição dos efeitos adversos de aflatoxinas em aves, perus e suínos. Diversos estudos comprovaram também que a bentonita sódica é um ótimo adsorvente para aflatoxinas em aves, do mesmo modo que as ASSCA (Mallmann et al., 2007).

Em virtude da grande probabilidade de contaminação dos ingredientes utilizados (LAMIC, 2007) nas rações, que podem apresentar níveis elevados e constantes de toxinas, e da carência de estudos sobre os efeitos das aflatoxinas e de adsorventes na criação de peixes com relevância a piscicultura, realizou-se este estudo para avaliar os efeitos de diversos níveis de aflatoxinas e adsorventes em rações sobre o desempenho, as taxas de sobrevivência e as características de carcaça de alevinos de jundiá (Rhamdia quelen).

\section{Material e Métodos}

O experimento foi conduzido na Estação de Piscicultura da Universidade Federal de Pelotas (UFPel), com duração de 49 dias, e as análises, no Laboratório de Nutrição Animal do Departamento de Zootecnia da UFPel. Foram utilizadas 36 caixas de polipropileno com capacidade de $250 \mathrm{~L}$, abastecidas com $200 \mathrm{~L}$ de água em um sistema de circulação fechado e termorregulado. O sistema tem capacidade de $20.000 \mathrm{~L}$ de água, abastecida por meio de um reservatório externo com água de um poço artesiano. A circulação da água nas unidades experimentais foi mantida com volume de 1,3 L/minuto, durante 24 horas por dia.

Utilizaram-se 360 alevinos de jundiá (Rhamdia quelen) com 4,2 $\pm 0,6 \mathrm{~g}$ de peso corporal, obtidos por reprodução induzida a partir de matrizes do próprio setor (UFPel) e criados em tanque de terra, alimentados com ração comercial (Tabela 1) contendo $45 \%$ de proteína bruta, além do plâncton originado por adubação.

Todos os peixes utilizados foram mantidos em jejum de 24 horas antes do início do experimento. Após o jejum, foram selecionados para as biometrias iniciais (peso e comprimento) e alojados em densidade de 10 alevinos por unidade experimental.

A alimentação foi ministrada duas vezes ao dia (9 e 16h), na proporção de $5 \%$ da biomassa. O ajuste da taxa de arraçoamento foi realizado pela biometria mensal de todos os alevinos de cada unidade experimental. Diariamente era feita a limpeza das caixas, por meio de sifão, retirando-se os resíduos e contabilizando eventual mortalidade. A troca diária de água foi em torno de $5 \%$, conforme a necessidade de sifonagem dos dejetos e resíduos das rações.

As dietas experimentais foram isoprotéicas e isocalóricas, contendo $35,2 \%$ de proteína bruta e $3.444 \mathrm{kcal} / \mathrm{kg}$ de energia digestível, conforme composição descrita por Coldebella \& Radünz Neto (2002).

As dietas foram preparadas no laboratório de Ictiologia do Departamento de Zootecnia. A matéria-prima utilizada na composição das dietas foi pesada, moída e misturada até completa homogeneização. Após o preparo, as misturas foram peletizadas em máquina elétrica de moer carne, mantidas em estufa por 48 horas a $50^{\circ} \mathrm{C}$ e novamente moídas até a obtenção de grânulos de $1 \mathrm{~mm}$. A alteração da granulometria foi realizada de acordo com o crescimento dos peixes para facilitar a apreensão do alimento. 
Tabela 1 - Composição da ração experimental

\begin{tabular}{|c|c|c|c|}
\hline \multicolumn{2}{|l|}{ Ingrediente } & \multicolumn{2}{|l|}{$\%$} \\
\hline Farinha de carne e ossos & 35,00 & 35,00 & 35,00 \\
\hline Farelo de soja & 24,01 & 24,01 & 24,01 \\
\hline Milho triturado & 19,21 & 19,21 & 19.21 \\
\hline Farelo de trigo & 7,00 & 6,70 & 6,4 \\
\hline Óleo de canola & 13,03 & 13,03 & 13,03 \\
\hline Sal comum iodado ${ }^{1}$ & 1,00 & 1,00 & 1,00 \\
\hline Premix vitamínico ${ }^{2}$ e mineral $^{3}$ & 0,75 & 0,75 & 0,75 \\
\hline Adsorvente $^{\circledR}$ (ASSCA) & 0 & 0,3 & 0,6 \\
\hline Total & 100 & 100 & 100 \\
\hline \multicolumn{4}{|l|}{ Nutriente $(\%)$} \\
\hline Proteína bruta & & 35,22 & \\
\hline Matéria seca & & 90,73 & \\
\hline Cinzas & & 10,65 & \\
\hline Extrato etéreo & & 16,16 & \\
\hline Fibra bruta & & 2,54 & \\
\hline Cálcio & & 3,20 & \\
\hline Fósforo & & 1,87 & \\
\hline Energia digestível, $\mathrm{kcal} / \mathrm{kg}$ & & $3.444,4$ & \\
\hline \multicolumn{4}{|c|}{$\begin{array}{l}{ }^{1} \text { Segundo Luchini (1990). } \\
2 \text { Composição do premix vitamínico (por kg): vit. A - } 6.000 .000 \mathrm{UI} \text {; vit. D - } \\
1.000 .000 \mathrm{UI} \text {; vit. E - } 100.000 \text {; vit. K - 5.000 UI; riboflavina - } 10.000 \mathrm{mg} \text {; ácido } \\
\text { pantotênico - } 30.000 \mathrm{mg} \text {; niacina - } 60.000 \mathrm{mg} \text {; vit. B12 - } 20.000 \mathrm{mcg} \text {; biotina - } \\
600 \mathrm{mcg} \text {; ácido fólico - } 2.500 \mathrm{mg} \text {; tiamina - } 10.000 \mathrm{mg} \text {; piridoxina - } 20.000 \mathrm{mg} \text {. } \\
{ }^{3} \text { Composição do premix mineral (por kg): cobre - } 12.001 \mathrm{mg} \text {; ferro - } 75.000 \mathrm{mg} \text {; } \\
\text { manganês - } 99.974 \mathrm{mg} \text {; iodo - } 998 \mathrm{mg} \text {; selênio - } 250 \mathrm{mg} \text {; zinco - } 90.001 \mathrm{mg} \text {. } \\
{ }^{\circledR} \text { ASSCA doada pela empresa Vulgel. }\end{array}$} \\
\hline
\end{tabular}

A aflatoxina foi produzida no Laboratório de Análises Micotoxicológicas - LAMIC-UFSM, de acordo com a metodologia apropriada, certificado pelo Instituto Nacional de Metrologia, Normalização e Qualidade Industrial e pelo Ministério da Agricultura, Pecuária e Abastecimento, por meio da fermentação de arroz parbolizado com uma cepa do fungo Aspergillus parasiticus. O arroz previamente esterilizado, depois de inoculado, foi adicionado a um erlenmayer e colocado em agitador orbital com controle de temperatura por seis dias. Posteriormente, o arroz foi moído e amostrado para quantificação das aflatoxinas (B1, B2, G1 e G2) por meio de cromatografia líquida de alta eficiência.

Os ingredientes utilizados na ração experimental estavam isentos de contaminação, conforme análise no LAMIC-UFSM. Esse cuidado se explica por tratar-se de inclusão artificial de aflatoxina na dieta sem que haja interferência de toxinas do próprio alimento. O pó de arroz fermentado (contendo aflatoxinas) foi acrescido à ração dos peixes, misturado a farelo de milho, e misturado aos demais ingredientes da ração em misturador mecânico com capacidade para $5 \mathrm{~kg}$. A ração foi peletizada e levada a estufa a $50^{\circ} \mathrm{C}$ ( 48 horas). Seqüencialmente, foi mantida em lugar seco, escuro e resfriado para evitar qualquer tipo de aparecimento e proliferação de outros fungos.
Uma fração de cada ração contendo um nível de aflatoxina foi enviada para o LAMIC para nova análise e quantificação das toxinas.

As rações foram adicionadas de aflatoxina nos níveis de $0 ; 150 ; 250$ ou $350 \mu \mathrm{g} / \mathrm{kg}$, associados ou não a 0,3 ou $0,6 \%$ adsorvente, totalizando 12 rações diferentes.

Aos 90 dias experimentais, após jejum de 24 horas, os peixes foram submetidos a biometria e pesagem para obtenção do peso médio final, do crescimento (comprimento total e padrão), do ganho de peso diário (peso final - peso inicial/período experimental), da biomassa (peso médio final - peso médio inicial*número de final de peixes), do rendimento de carcaça (peso do peixe eviscerado*100/ peso final), do fator de condição corporal (peso médio total/comprimento total $l^{3} \times 100$ ) e da taxa de sobrevivência.

O rendimento de carcaça foi avaliado em amostra retiradas de dez alevinos de cada ração no final do experimento e determinado pelo cálculo do peso total dos peixes subtraído do peso das vísceras, expresso em porcentagem, conforme descrito por Melo (2002).

Também foram monitorados diariamente ( 9 e 16 h) os parâmetros de qualidade da água nas unidades experimentais (oxigênio dissolvido, amônia total, alcalinidade, $\mathrm{pH}$ e temperatura) com auxílio de um oxímetro digital e kit colorimétrico.

O delineamento experimental foi inteiramente casualizado, com níveis de aflatoxinas, com e sem inclusão de adsorventes, cada um com três repetições. Os resultados foram submetidos a ANOVA para comparação entre as médias, ao teste Tukey ( $5 \%$ ) e à análise de contrastes (SAS, 1997).

\section{Resultados e Discussão}

Os valores dos parâmetros físico-químicos da água dos aquários, temperatura média, oxigênio dissolvido, amônia total, alcalinidade e $\mathrm{pH}$ foram, respectivamente: temperatura da água: $24,5 \pm 2,1^{\circ} \mathrm{C}$, oxigênio dissolvido: $5,6 \pm 1,1 \mathrm{mg} / \mathrm{L}$, amônia total: $0,5 \pm 0,1 \mathrm{mg} / \mathrm{L}$, alcalinidade: $52 \pm 5,9 \mathrm{mg} / \mathrm{L} \mathrm{e} \mathrm{pH}$ $7,5 \pm 0,3$; e estão dentro da faixa recomendada por Boyd (1997) para peixes e por Chippari-Gomes et al. (2000) e Piedras et al. (2004) para jundiá.

Os peixes alimentados com as rações contendo aflatoxinas $(150,250$ e $350 \mu \mathrm{g} / \mathrm{kg})$ apresentaram diferença $(\mathrm{P}=0,001)$ no crescimento (padrão e total) e no peso em relação àqueles alimentados com a ração controle, o que resultou em redução acentuada no ganho de peso, em torno de $42 \%$ no maior nível de aflatoxina $(350 \mu \mathrm{g} / \mathrm{kg})$ (Tabela 2). 
O ganho diário de peso, o fator de condição corporal e a biomassa também diferiram significativamente $(\mathrm{P}=0,0001)$ dos obtidos com a ração controle, sem aflatoxina ou adsorventes. O rendimento de carcaça e a taxa de sobrevivência, no entanto, não diferiram entre os níveis de aflatoxina (Tabela 3).

Resultados semelhantes foram encontrados em alevinos de jundiá por Lopes et al. (2005), que verificaram diminuição de ganho de peso, ganho médio diário, comprimento padrão e total. $\mathrm{O}$ fator de condição corporal, no entanto, diferiu entre os alevinos alimentados com as rações sem adsorventes $(0,3$ e $0,6 \%)$, o que contrasta com os resultados obtidos por Lopes et al. (2005), que observaram que, no nível de aflatoxina de $204 \mu \mathrm{g} / \mathrm{kg}$, não houve diferença significativa no rendimento de carcaça e no fator de condição corporal. Tuan et al. (2002), testando níveis de 100 ppm de aflatoxina B1 por kg na dieta de alevinos de tilápia-do-nilo (Oreochromis niloticus), observaram acentuada redução do ganho de peso, porém com mortalidade. Aranas et al. (2002) também observaram redução de ganho de peso em alevinos de tilápia-do-nilo alimentados com níveis de $80 \mu \mathrm{g} / \mathrm{kg}$ na dieta.

Manning et al. (2005) alimentaram alevinos de channel catfish (Ictalurus punctatus) com $20 \mu \mathrm{g} / \mathrm{kg}$ em uma dieta prática e observaram que não houve diminuição no ganho de peso e consumo alimentar, o que comprova que esta espécie é resistente a toxina. Resistência à intoxicação por aflatoxina também foi observada por Sahoo \& Mukherjee (2002), que, ao injetarem aflatoxinas intramuscular $(1,25 \mathrm{mg} / \mathrm{kg}$ por peixe) por 60 dias em alevinos de rohu (Labeo rohhita), não observaram mortalidade, apesar da redução do ganho de peso.

Houve pequena redução no ganho de peso dos alevinos, que pode estar relacionada aos efeitos do adsorvente, que

Tabela 2 - Desempenho de alevinos de jundiá alimentados com rações contendo aflatoxinas e adsorventes

\begin{tabular}{|c|c|c|c|c|c|}
\hline & & Peso inicial $(\mathrm{g})$ & Peso final $(\mathrm{g})$ & Comprimento total $(\mathrm{cm})$ & Comprimento padrão $(\mathrm{cm})$ \\
\hline \multirow{2}{*}{ Aflatoxina $(\mu \mathrm{g} / \mathrm{kg})$} & 150 & $4,4 \pm 0,70 \mathrm{a}$ & $14,60 \pm 3,3 \mathrm{bA}$ & $12,26 \pm 0,8 \mathrm{bA}$ & $10,04 \pm 0,7 \mathrm{bA}$ \\
\hline & 350 & $4,9 \pm 0,90 \mathrm{a}$ & $15,21 \pm 3,7 \mathrm{bA}$ & $12,68 \pm 0,9 \mathrm{bA}$ & $10,50 \pm 0,9 \mathrm{bA}$ \\
\hline \multirow{2}{*}{$\begin{array}{l}\text { Aflatoxina }+0,3 \\
\text { adsorvente }\end{array}$} & Controle & $4,6 \pm 0,90 a$ & $22,6 \pm 6,1 \mathrm{aA}$ & $14,37 \pm 1,1 \mathrm{aA}$ & $11,85 \pm 0,9 \mathrm{aA}$ \\
\hline & 350 & $4,2 \pm 0,70 \mathrm{a}$ & $10,0 \pm 2,9 \mathrm{bB}$ & $10,86 \pm 1,1 \mathrm{bA}$ & $8,88 \pm 1,02 \mathrm{bA}$ \\
\hline \multirow{4}{*}{$\begin{array}{l}\text { Aflatoxina }+0,6 \% \\
\text { adsorvente }\end{array}$} & Controle & $4,8 \pm 0,72$ & $18,73 \pm 2,6 \mathrm{aB}$ & $13,60 \pm 0,63 \mathrm{aA}$ & $11,35 \pm 0,50 \mathrm{aB}$ \\
\hline & 150 & $4,2 \pm 0,80 \mathrm{a}$ & $9,38 \pm 1,3 \mathrm{bB}$ & $9,70 \pm 0,7 \mathrm{bA}$ & $8,61 \pm 0,6 \mathrm{bA}$ \\
\hline & 250 & $4,3 \pm 0,73 \mathrm{a}$ & $10,33 \pm 3,4 \mathrm{bB}$ & $10,74 \pm 1,2 \mathrm{bA}$ & $8,9 \pm 1,01 \mathrm{bA}$ \\
\hline & 350 & $4,4 \pm 0,80 \mathrm{a}$ & $9,41 \pm 2,9 \mathrm{bB}$ & $10,62 \pm 1,1 \mathrm{bA}$ & $8,8 \pm 0,89 \mathrm{bA}$ \\
\hline
\end{tabular}

Letras minúsculas diferentes nas colunas, dentro de cada nível de aflatoxina ou adsorvente, indicam diferença significativa ( $(\mathrm{P}<0,05)$.

Letras maiúsculas diferentes nas colunas, para cada nível entre os tratamentos, apresentam diferença significativa $(\mathrm{P}<0,05)$.

Tabela 3 - Desempenho dos alevinos de jundiá após 90 dias experimentais alimentados com rações contendo aflatoxinas e adsorventes

\begin{tabular}{lccccc}
\hline & & Ganho de peso diário $(\mathrm{g})$ & Rendimento de carcaça $(\%)$ & Fator de condição corporal & Sobrevivência $(\%)$ \\
\hline Aflatoxina $(\mu \mathrm{g} / \mathrm{kg})$ & Controle & $0,22 \pm 0,1 \mathrm{aA}$ & $89,98 \pm 9,7 \mathrm{aA}$ & $0,82 \pm 0,13 \mathrm{aA}$ & 100 \\
& 150 & $0,11 \pm 0,03 \mathrm{bA}$ & $88,70 \pm 2,0 \mathrm{aA}$ & $0,78 \pm 0,05 \mathrm{bA}$ & 100 \\
& 250 & $0,13 \pm 0,03 \mathrm{bA}$ & $89,44 \pm 2,3 \mathrm{aA}$ & $0,79 \pm 0,07 \mathrm{bA}$ & 100 \\
& 350 & $0,11 \pm 0,04 \mathrm{bA}$ & $89,19 \pm 1,3 \mathrm{aA}$ & $0,73 \pm 0,04 \mathrm{bA}$ & 100 \\
\hline Aflatoxina $+0,3$ & Controle & $0,19 \pm 0,06 \mathrm{aA}$ & $88,81 \pm 1,5 \mathrm{aA}$ & $0,75 \pm 0,05 \mathrm{aA}$ & 100 \\
adsorvente & 150 & $0,10 \pm 0,03 \mathrm{bB}$ & $87,88 \pm 3,5 \mathrm{aA}$ & $0,74 \pm 0,05 \mathrm{aB}$ & 100 \\
& 250 & $0,09 \pm 0,04 \mathrm{bB}$ & $89,88 \pm 4,1 \mathrm{aA}$ & $0,74 \pm 0,05 \mathrm{aB}$ & 100 \\
& 350 & $0,07 \pm 0,03 \mathrm{bB}$ & $88,61 \pm 1,5 \mathrm{aA}$ & $0,73 \pm 0,05 \mathrm{aA}$ & 100 \\
\hline Aflatoxina $+0,6 \%$ & Controle & $0,15 \pm 0,02 \mathrm{aB}$ & $89,98 \pm 0,75 \mathrm{aA}$ & $0,74 \pm 0,11 \mathrm{aA}$ & 100 \\
adsorvente & 150 & $0,05 \pm 0,01 \mathrm{bC}$ & $88,42 \pm 4,1 \mathrm{aA}$ & $0,73 \pm 0,15 \mathrm{aB}$ & 100 \\
& 250 & $0,06 \pm 0,04 \mathrm{bB}$ & $89,74 \pm 1,2 \mathrm{aA}$ & $0,73 \pm 0,07 \mathrm{aB}$ & 100 \\
CV (\%) & 350 & $0,05 \pm 0,03 \mathrm{bB}$ & $89,77 \pm 1,3 \mathrm{aA}$ & $0,72 \pm 0,07 \mathrm{aA}$ & 14,48
\end{tabular}

Letras minúsculas diferentes nas colunas, dentro de cada nível de aflatoxina ou adsorvente, indicam diferença significativa ( $\mathrm{P}<0,05)$.

Letras maiúsculas diferentes nas colunas, para cada nível entre os tratamentos, indicam diferença significativa $(\mathrm{P}<0,05)$. 
alterou a palatabilidade da dieta e, desta forma, apresentou diferença significativa entre as rações controle (sem aflatoxinas) e controle com $0,6 \%$ de adsorvente.

Os valores de ganho de peso diário obtidos com as rações sem aflatoxinas (com e sem adsorvente) diferiram ( $\mathrm{P}=0,0001)$ dentro de cada nível de aflatoxina. Além disso, observou-se também diminuição no ganho com o aumento dos níveis de adsorvente na dieta. Valores semelhantes também foram encontrados por Lopes et al. (2005), de $0,23 \mathrm{~g}$ de ganho de peso médio diário, com ração controle para alevinos de jundiá em 45 dias experimentais. De certa forma, o peso corporal dos alevinos de jundiá foi proporcional ao crescimento (padrão e total), pois houve diferença significativa no fator de condição corporal, de modo que a ração controle, sem adsorvente, resultou em índice de 0,82 , e, com a inclusão de aflatoxina, o fator de condição corporal baixou até valores de 0,72 (Tabela 3). Esses resultados são relativamente inferiores dos relatados por Lopes et al. (2005), índice de 0,89 para a ração controle e índice de 0,80 no maior nível de aflatoxina $(204 \mu \mathrm{g} / \mathrm{kg})$.

De acordo com Dilkin (2002), consumos em doses moderadas a baixas causam aflatoxicose crônica, desencadeando graves problemas imunossupressivos, perda de ganho de peso e taxa de crescimento. Os valores observados para rendimento de carcaça entre os níveis de aflatoxina e adsorventes não apresentaram diferença significativa ( $\mathrm{P}>0,05)$ e mantiveram-se em $88,89 \%$. Resultados semelhantes $(82,16 \%)$ foram descritos por Lopes et al. (2205), de $204 \mu \mathrm{g} / \mathrm{kg}$ para alevinos de jundiá.

Em relação à sobrevivência no experimento, pode-se afirmar que os jundiás apresentam alta tolerância a intoxicação por aflatoxinas. Resultados semelhantes foram encontrados por Lopes et al. (2005) em jundiá intoxicados por 35 dias com níveis de aflatoxina de 41 a $204 \mu \mathrm{g} / \mathrm{kg}$, que apresentaram $100 \%$ de sobrevivência, embora Chavez-Sanchez et al. (1994) tenham constatado que a inclusão de aflatoxina até $20 \mathrm{mg} / \mathrm{kg}$ na dieta de alevinos de tilápias após 25 dias causou elevada mortalidade. Tuan et al. (2002) também observaram mortalidade de $60 \%$ em alevinos de tilápias alimentados por 8 semanas com rações contendo aflatoxina $(100 \mathrm{mg} / \mathrm{kg})$. Todavia, Farabi et al. (2006) observaram mortalidade de 8,6\% quando alimentaram juvenis de Huso huso com ração contaminada com $10 \mu \mathrm{g} / \mathrm{kg}$ durante 40 dias.

Ao longo dos 90 dias experimentais, observou-se resistência dos alevinos à intoxicação por aflatoxinas, porém algumas características morfológicas, como despigmentação parcial da pele, próxima à nadadeira caudal, foram observadas em todos os alevinos alimentados com rações contaminadas. Esses resultados indicam variação da sensibilidade dos peixes à toxicidade aguda a aflatoxina. Sinais de aflatoxicose também foram observados por Farabi et al. (2006) em juvenis de Huso huso alimentados com rações contaminadas com aflatoxinas.

Os efeitos tóxicos das aflatoxinas dependem da dose e do tempo de exposição e determinam intoxicação aguda e crônica. A síndrome tóxica aguda ocorre pela ingestão de alimento com alta concentração de aflatoxinas e os efeitos são observados em curto espaço de tempo e incluem rápida deterioração do estado geral do animal, perda de apetite, hepatite aguda, hemorragias e morte (Rosmaninho et al., 2001).

Quando as micotoxinas são ingeridas, seus efeitos ocasionam diferenças nas estruturas químicas, influenciadas pelo fato de serem ingeridas por diferentes organismos animais superiores e também pela diversidade de espécies, raça, sexo, idade, fatores ambientais, manejo, condições nutricionais e outras substâncias (Dilkin, 2002).

Os valores de desempenho zootécnicos não diferiram com a utilização de adsorventes (ASSCA) na ração, entretanto, o adsorvente ocasionou diferença significativa $(\mathrm{P}<0,05)$ no desempenho, como peso, ganho de peso diário, biomassa e fator de condição corporal, nos alevinos alimentados com as rações contendo aflatoxina (Tabelas 2 e 3 ).

Desta forma, pode se afirmar que a adição de adsorventes $(0,3$ e $0,6 \%)$ em rações para alevinos prejudicou os índices de desempenho. Ellis et al. (2000), testando adsorvente (bentonita sódica) em trutas (Oncorhynchus mykiss) alimentadas com rações contendo aflatoxinas $(20 \mu \mathrm{g} / \mathrm{kg})$, afirmaram que a inclusão de $2 \%$ de adsorvente na ração reduz significativamente a absorção das aflatoxinas pelo organismo animal. Este fator de absorção é atribuído a sua alta afinidade eletrolítica, por micotoxinas de elevada polarida, como a aflatoxina (Huwig et al., 2001).

Segundo Ouhida et al. (2000), os benefícios da utilização do adsorvente na ração sobre o ganho de peso e a conversão alimentar ainda não são bem definidos, portanto, há necessidade de utilizar níveis altos (6\%), uma vez que, em outros organismos monogástricos, níveis de $2 \%$ de bentonita sódica na dieta não foram suficientes para absorver as micotoxinas. Entretanto, Tomasevic-Canovic et al. (2003) afirmaram que a preparação e o processo de elaboração e inclusão do adsorvente na dieta influencia na absorção das micotoxinas.

Os peixes nesta pesquisa não aceitaram muito bem a ração contendo adsorvente, com isso, a perda de ganho de peso pode ter sido ocasionada pela palatabilidade da dieta ou até mesmo pela absorção de nutrientes pelo adsorvente, pois, de acordo com Döll et al. (2005), a modificação químicas desses minerais também pode ter efeito sobre a absorção de nutrientes pelos animais. 
Os efeitos negativos na produtividade de peixes causados por aflatoxinas no desenvolvimento dos peixes e a presença das micotoxinas nos ingredientes (LAMIC, 2007) que compõem as rações devem ser monitorados. É importante dar continuidade a esse tipo de investigação para buscar resultados mais conclusivos, principalmente pela ação do adsorvente no desenvolvimento dos peixes.

\section{Conclusões}

Os níveis crescentes de aflatoxinas na dieta causaram redução no crescimento e ganho de peso nos alevinos de jundiá. O adsorvente não beneficiou o desenvolvimento dos alevinos nas concentrações testadas.

\section{Agradecimentos}

À Universidade Federal de Pelotas, pela disponibilização de laboratórios e pessoal técnico capacitado para a execução da pesquisa; e aos funcionários da Estação de Piscicultura da UFPel, pelo empenho e pela colaboração na realização do experimento em campo. Ao Laboratório de Análise de Micotoxinas da UFSM, pelas micotoxinas e análises. À CAPES e ao CNPq, pelo apoio financeiro.

\section{Literatura Citada}

ARANAS, S.; TABATA, Y.A.; SABINO, M. et al. Differential effect of chronic aflatoxin B1 intoxication on the growth performance and incidence of hepatic in triploid and diploid rainbow trout (Oncorhynchus mykiss). Archives Medical Veterinary, v.34, n.2, p.253-263, 2002.

BOYD, C. Manejo do solo e da qualidade da água em viveiro para aqüicultura. São Paulo: Mogiana Alimentos S.A., 1997. 55p.

CHÁVEZ-SÁNCHEZ, M.C.; MARTÍNEZ PALACIOS, C.A; OSORIO MORENO, I. Pathological effects of feeding young Orechromis niloticus diets supllemented with different levels of aflatoxin B1. Aquaculture, v.127, p.49-60, 1994.

CHIPPARI-GOMES, A.R.; GOMES, L.C.; BALDISSEROTTO, B. Lethal temperatures for Rhamdia quelen larvae (Pimelodidae). Ciência Rural, v.30, n.6, p.1069-1071, 2000.

CONROY, G. Alteraciones asociadas con dos alimentos comerciales en tetrahibridos de tilápia roja cultivados en Venezuela. Caracas: Associación Americana de Soya, 2000. 33p. (Boletin Informativo).

COLDEBELlA, I.; RADÜNZ NETO, J. Farelo de soja na alimentação de alevinos de jundiá Rhamdia quelen. Ciência Rural, v.32, n.3, p.499-503, 2002.

DILKIN, P. Micotoxicose suína: aspectos preventivos, clínicos e patológicos. Biológico, v.64, n.2, p.187-191, 2002.

DÖLL, S.; GERICKE, S.; DÄNICKE, S. et al. The efficacy of a modified aluminosilicate as a detoxifying agent in Fusarium toxin contaminated maize containing diets for piglets. Journal of Animal Physiology and Animal Nutrition, v. 89, n.9-10, p.342-358, 2005.

ELLIS, R.W.; CLEMENTS, M.; TIBBETTS, A. et al. Reduction of the biovailability of $20 \mathrm{mg} / \mathrm{kg}$ aflatoxin in trout feed containing clay. Aquaculture, v.183, p.179-188, 2000.
FARABI, S.M.V.; YOUSEFIA, M.; HAJIMORADLOO, A. Aflatoxicosis in juvenile Huso huso fed a contamined diet Journal of Applied Ichthyology, v.22, p.234-237, 2006 (suppl. 1)

FERREIRA, H.; PITTNER, E.; SANCHES, H.F. et al. Aflatoxinas: um risco à saúde animal. Ambiência, v.2, n.1, p.113-127, 2006.

FURUYA, V.R.B.; HAYASHI, C.; FURUYA, W.M. Farelo de canola na alimentação da tilápia do Nilo (Oreochromis niloticus L.), durante o período de reversão de sexo. Revista Brasileira de Zootecnia, v.26, n.6, p.1067-1073, 1997.

LABORATÓRIO DE ANÁLISES MICOTOXICOLÓGICAS LAMIC. [2007] Universidade Federal de Santa Maria, Santa Maria-RS, Brasil. Tabelas de resultados. Disponível em: $<$ http://www.lamic.ufsm.br/resultado de qualidade.htm $>$ Acesso em: $11 / 11 / 2007$.

LUCHINI, L. Manual para el cultivo del bagre sudamericano (Rhamdia sapo). Santiago do Chile: FAO, 1990. 63p.

HUIG, A.; FREIMUND, S.; KÄPPELIB, O. et al. Mycotoxin detoxication of animal feed by different absorvents. Toxicology Letters, v.122, n.2, p.179-188, 2001.

LOPES, P.R.S.; RADÜNZ NETO, J.; MALLMANN, C.A. et al. Crescimento e alterações no fígado e na carcaça de alevinos de jundiá alimentados com dietas com aflatoxinas. Pesquisa Agropecuária Brasileira, v.40, n.10, p.1029-1034, 2005.

MALLMANN, C.A.; GIACOMINI, L.Z.; RAUBER, H.R. et al. Micotoxinas em ingredientes para alimento balanceado de aves In: CONGRESSO LATINOAMERICANO DE AVICULTURA, 20. 2007, Porto Alegre. Anais... Porto Alegre: 2007. p.191-204

MANNING, B.B.; LI, M.H.; ROBINSON, E.H. Aflatoxins from moldy corn cause no reductions in channel catfish Ictalurus punctutus performance. Journal of the World Aquaculture Society, v.36, n.1, p.59-67, 2005.

MEER, M.B.; MACHIELS, M.A.M.; VERDEGEM, M.C.J. The effect of dietary protein level on growth, protein utilization and body composition of Colossoma macropomum (Cuvier). Aquaculture Research, v.26, n.12, p.901-909, 1995.

MELO, J.F.B.; RADÜNZ NETO, J.; SILVA, J.H. et al. Desenvolvimento e composição de alevinos de jundiá (Rhamdia quelen) alimentados com dietas contendo diferentes fontes de lipídio. Ciência Rural, v.32, n.2, p.323-327, 2002.

MIAZZO, R.; PERALTA, M.F.; MAGNOLI, C. et al. Efficacy of sodium bentonite as a detoxifier of broiler feed contaminated with aflatoxin and fumonisin. Poultry Science, v.84, p.1-8, 2005.

OGIDO R.; OLIVEIRA C.A.; LEDOUX, D.R. et al. Effects of prolonged administration of aflatoxins B1 and fumonisin B1 in laying Japanese quail. Poultry Science, v.83, p.1953-1958, 2004.

OLVER, M.D. Effect of feeding clinoptilolite (zeolite) on the performance of three strains of laying hens. British Poultry Science, v.38, p.220-222, 1997.

PIEDRAS, S.R.N.; MORAES, P.R.R.; POUEY, J.L.O.F. Crescimento de juvenil de jundiá (Rhamdia quelen). Boletim do Instituto de Pesca, v.30, n.2, p.177-182, 2004

UHIDA, I.; PEREZ, J.F.; GASA, J. The effects of sepiolite in broiler chicken diets of high, medium and low viscosity: productive performance and nutritive value. Animal Feed Science and Technology, v.85, p.183-194, 2000.

ROSMANINHO, J.F.; OLIVEIRA, C.A.F.; BITTENCOURT, A.B.F Efeitos das micotoxicoses crônicas na produção avícola. Arquivos do Instituto de Biologia, v.68, p.107-114, 2001.

SAHOO, P.K.; MUKHERJEE, S.C. Influence of high dietary atocopherol intakes on specific immune response, nonspecific resistance factors and disease resistance of healthy and aflatoxin B1-induced immunocompromised Indian major carp, Labeo rohita (Hamilton). Aquaculture Nutrition, v. 8 , p. $159-167,2002$

SANTÚRIO, J.M. Impacto das aflatoxinas sobre a produção animal. Perspectiva latino-americana. In: CONFERÊNCIA APINCO 97 DE CIÊNCIA E TECNOLOGIA AVÍCOLA, 1996, Campinas. 
Anais... Universidade Federal Rural do Rio de Janeiro, 1997. p.149-56.

STATISTICAL ANALISYS SYSTEM - SAS. User's guide. Versão 6, 4.ed. Cary: SAS Institute, 1997. 846p.

TRISTAN, T.Q. Dinâmica toxicológica de aflatoxinas em alimentos de origen animal em Aguascalientes y Querétaro. Santiago de Querétaro: Consejo Nacional de Ciência y Tecnologia; Edicion Comunicación del Centro, 2002. $117 \mathrm{p}$.

TUAN, A.N.; GRIZZLE, J.M.; LOVELL, R.T. et al. Growth and hepatic lesions of Nile Tilapia Oreochromis niloticus fed diets containing aflatoxin $B_{1}$. Aquaculture, v.212, p.311-319, 2002.
TOMASEVIC-CANOVIC, M.; DAKOVIC, A.; ROTTINGHAUS, A. et al. Surfactant modified zeolites - new efficient adsorbents for micotoxins. Microporous and Mesoporous Materials, v.61, p.173-180, 2003

VIEIRA, V.L.P.; RADUNS NETO, J.; LOPES, P.R.S. et al. Alterações metabólicas e hematológicas em jundiás (Rhamdia quelen) alimentados com rações contendo aflatoxinas Ciência Animal Brasileira, v.7, n.1, p.49-55, 2006.

YU, J.; CLEVELAND, T.E.; NIERMAN, W.C. et al. Aspergillus flavus genomics: gateway to human and animal health, food safety, and crop resistance to diseases. Revista Iberoamericana de Micologia, v.22, p.194-202, 2005. 